\title{
Editorial: Observational studies in ADHD: the effects of switching to modified-release methylphenidate preparations on clinical outcomes and adherence
}

\author{
Aribert Rothenberger · Manfred Döpfner
}

Published online: 8 September 2011

(C) The Author(s) 2011. This article is published with open access at Springerlink.com

\begin{abstract}
Patients with ADHD may have better adherence to treatment with modified-release methylphenidate (MPH-MR) formulations, which are taken once daily, compared with immediate-release (IR) formulations, which need to be taken several times a day. Data on long-term outcomes such as adherence may be lacking from randomised controlled trials as these are usually only shortterm. Observational studies, if performed and reported appropriately, can provide valuable long-term data on such outcomes, as well as additional information on effectiveness and efficiency, from a real-life setting. By reviewing previous observational studies that have investigated switching treatment from MPH-IR to MPH-MR, results from a new, naturalistic observational study, the OBSEER study, are put into context. We conclude that, based on observational trial data, switching from MPH-IR to MPHMR is a valid clinical approach, with the potential for improved clinical outcome and treatment adherence.
\end{abstract}

Keywords Observational trials - ADHD - Children · Methylphenidate $\cdot$ Switching

\section{Introduction}

Randomised controlled trials (RCTs) in attention deficit hyperactivity disorder (ADHD) have shown that long-acting

\footnotetext{
A. Rothenberger $(\bowtie)$

Department of Child and Adolescent Psychiatry, University of Göttingen, Von-Siebold-Str. 5, 37075 Göttingen, Germany e-mail: arothen@gwdg.de

M. Döpfner

Department of Child and Adolescent Psychiatry,

University of Cologne, Cologne, Germany
}

methylphenidate (MPH) preparations have similar efficacy to multiple doses of short-acting, immediate-release (IR) formulations, but with the advantage of convenient oncedaily dosing [4, 15, 16]. Patients receiving long-acting or modified-release (MR), formulations may have better treatment adherence than those receiving MPH-IR [8]. However, this is still a matter of debate as RCTs of MPH are usually only short-term (i.e. a few weeks' duration) and the patient population is highly selected; therefore, results from RCTs do not fully represent long-term treatment or the heterogeneous population of patients with ADHD found in daily clinical practice. To learn more about adequate individualised treatment with $\mathrm{MPH}$ preparations in a real-world setting, and to obtain a clearer picture of effectiveness ("is it of use?") and efficiency ("how much benefit at what cost?"), studies of treatment approaches beyond the RCT setting are necessary [29]. The general trend for increasing use of MPH-MR preparations in ADHD [23, 34] means that post-RCT observational studies are required to ensure well-monitored, up-to-date drug management. Furthermore, there is a need for an evidencebased, long-term perspective for patients [22].

In paediatric psychopathology, the boundaries between 'observational' and 'experimental' studies are considered indistinct [26], with observational studies generally used predominantly in epidemiology and less so for clinical purposes. However, clinical observational studies may be useful in generating additional, often more definitive, conclusions about treatment guidance and safety effects (especially over the long-term), or the natural history of a disorder. Such findings can complement the results obtained from the experimental studies [29], which are a pre-condition for drug treatment evaluation. Thus, RCTs and observational studies can each make a useful contribution to the evaluation of treatment effectiveness. 


\section{Strengths and weaknesses of RCTs and observational trials}

The RCT is seen by many as the 'gold standard' as it should, by design, ensure that patients being compared differ only in their exposure to the intervention under study [7]. In fact, both randomised and non-randomised trial designs have their own particular limitations. Issues related to the process of randomisation that may affect the validity of conclusions drawn from the results of RCTs and non-randomised studies were explored in a systematic review [7]. Here, non-randomised studies were considered to include quasi-experiments, natural experiments and prospective, observational, cohort studies. Results showed that RCTs and non-randomised studies can produce different results but the direction of the difference is not consistent-i.e. neither method consistently favoured intervention over placebo or new treatment over old [7]. Furthermore, neither method gave consistently larger estimates of treatment effect. Opposing opinions about the relative merits of RCTs and non-randomised studies may be underpinned by differences in threats to validity between the two study designs [7], which can be external (the extent to which the results are generalisable to all potential recipients), or internal (whether differences in observed effects can be attributed to differences in the intervention) [25]. RCTs may lack external validity in that those who meet eligibility criteria, or are invited, or agree to participate are significantly different to the population to whom the results of the study will be applied, and so the clinical usefulness of the study may be limited. Although evidence is limited, there is a tendency for settings of non-randomised studies to be slightly more representative of those who are eligible to be included [7]. Non-randomised studies also include other real-world effects, for example patients' preferences [25, 30], or the doctor-patient relationship [30], increasing their external validity. However, a major criticism of non-randomised studies is the possibility that groups being compared differ prognostically in important characteristics, affecting the internal validity of such trials [7]. Clearly, for best effect, internal and external validity need to be balanced against each other. Interestingly, despite their methodological differences, the systematic review found that the differences in results between RCTs and non-randomised studies are frequently smaller than those between RCTs or between nonrandomised studies [7].

\section{Avoiding pitfalls in observational trials}

As observational studies are broader in scope and less rigorous than RCTs, they may be prone to certain pitfalls. Observational studies, including those sponsored by pharmaceutical companies, should be designed in such a way that the scientific merit of the study has the highest priority and secondary aspects are minimised [29]. To avoid methodological shortcomings, several points need to be considered [19], including:

- selection bias (e.g. is the sample representative for the population in mind? Are subgroups comparable?)

- information bias (e.g. is all information gathered in a similar way?)

- measurement errors (e.g. are inventories psychometrically sound? Are measurement limitations considered?)

- evaluation problems (e.g. is the study design appropriate? Is quality control of data sampling included? How is the handling of confounders planned? Are biostatistics adequate?).

Awareness of these possible pitfalls should mean that they can be avoided by the use of an appropriate study design, or at least that any weaknesses and limitations can be considered when reporting and interpreting the data. Reporting of an observational study is only as good as the data behind it. Therefore, it would be advantageous for investigators to consider all 22 points of the STROBE (STrengthening the Reporting of OBservational studies in Epidemiology) consortium checklist $[1,32]$ when planning an observational study as well as when reporting it. Aside from study design, the guidelines governing what data can be collected in observational studies vary between countries, so what may require ethics approval in one country would not in another. This also means that reporting these studies can be problematic if, for example, the regulations in the country in which the journal is published require ethics approval even though the country in which the data were collected did not [10].

\section{Switching between ADHD drug treatments and patient adherence}

Treatment with MPH may improve symptoms of ADHD in about $75 \%$ of patients, and response rates of up to $90 \%$ can be achieved by switching unresponsive patients to other stimulants (e.g. amphetamine sulphate) [5]. This leaves at least $10 \%$ of patients who do not benefit from stimulants, and for whom other medications (e.g. atomoxetine, guanfacine) may be considered. In addition, it is still not clear how much of an improvement can be achieved if one MPH preparation is replaced by another at an equivalent dose. This question is of particular interest when considering a switch from MPH-IR to MPH-MR, with the potential for more convenient dosing, less stigmatisation and potentially better adherence as MPH-MR only has to be administered once daily in the morning. 
Good adherence to therapy is of utmost importance, especially in chronic mental health conditions such as ADHD, and must be considered in addition to the effectiveness and efficiency of an intervention. During treatment with MPH-IR preparations in ADHD, poor adherence is a critical issue, ranging from 20 to $80 \%$ after 1 year, with adherence rates of $40-50 \%$ after 3-5 years [2]. Following parental complaints about social stigmatisation, and the inconvenience of handling multiple doses during the day, it was hoped that adherence would be improved by developing once-daily MPH preparations. However, better rates of adherence do not necessarily follow from switching to an improved formulation, as there could be other clinical and social factors involved that are associated with the disorganised and oppositional behaviours of patients with ADHD and their families. For this reason, it is important to investigate all drug- and non-drug-related aspects of adherence when using MPH-MR preparations for the treatment of ADHD in the daily clinical setting.

\section{Switching of MPH preparations in observational studies}

Although previous RCTs have compared MPH-IR, MPHMR and placebo [15, 16], such trials do not provide any information about the clinical effects resulting from switching from MPH-IR to MPH-MR during the study protocol. Observational studies may be better suited to investigating these effects, but to date only a few observational studies of switching to MPH-MR formulations have been reported, investigating the switch to treatment with OROS $^{\circledR}$ MPH (Concerta ${ }^{\circledR}$, Janssen-Cilag, UK) [27], MPH-SODAS ${ }^{\circledR}$ (Ritalin $^{\circledR}$-LA, Novartis, US) [24], Medikinet $^{\circledR}$ retard/XL (Medice, Germany) [13] and Equasym $\mathrm{XL}^{\circledR 1}$ (Shire Pharmaceuticals Ireland Limited, Ireland) $[11,12]$.

One of the open-label studies was a multicentre, European study of OROS ${ }^{\circledR} \mathrm{MPH}$, which included 150 children (aged 6-16 years) with ADHD who were stable on MPHIR treatment before switching [27]. The German subgroup of 50 patients was increased afterwards to 221 patients and data were analysed separately $[20,21]$. In the first 3-week phase (European and German study), children benefited from switching formulations, but IOWA Conners scores improved only for parent ratings; teachers did not recognise a change in behaviour. The global effectiveness

\footnotetext{
${ }^{1}$ Equasym $\mathrm{XL}$ is the UK trade name, and is registered and marketed by Shire in the following countries under the following trademarks: Denmark, Equasym Depot; Finland, Equasym Retard; France, Quasym LP; Germany, Equasym Retard; Ireland, Equasym XL; Netherlands, Equasym XL; Norway, Equasym Depot; Sweden, Equasym Depot; South Korea, Metadate CD; Mexico, Metadate CD. Information correct at August 2011.
}

evaluation was positive, i.e. 'very good' or 'good' (German study: teachers $55 \%$, investigators $77 \%$, parents $79 \%$ ) [20]. Tolerability of OROS $^{\circledR}$ MPH was also good, with about $90 \%$ of parents favouring continuation of the MPH switch, a good predictor for better adherence in the long-term. These results are notable because the preceding treatment with MPH-IR had already reduced the symptoms of ADHD. For comparison, a score of 10 is usual on the parent IOWA Conners scale inattention/hyperactivity for unmedicated children with ADHD [20]. In the OROS $^{\circledR}$ MPH study, the baseline score (i.e. after treatment with MPH-IR, but before switching to MR) was 6.4 , which decreased further to 4.2 after 21 days of treatment with OROS $^{\circledR}$ MPH. Thus, switching resulted in an additional statistically significant and clinically relevant treatment effect [20]. However, one should be cautious about drawing firm conclusions: this was an open study, the starting dose was heterogeneous and there was a tendency to increase doses while switching (which may be interpreted as dose optimisation). Also, the discrepancy between parent and teacher evaluation in the IOWA Conners scale may be due to both a pharmacokinetic weakness of the OROS ${ }^{\circledR}$ MPH formulation in the morning (lower MPH availability) and a pharmacokinetic strength in the afternoon (better symptom control). In summary, one can agree with Heger et al. [20] that 'the results of this German sample suggest that children and adolescents with ADHD achieve at least as good control of central ADHD symptoms if there is a switch from MPH-IR to OROS ${ }^{\circledR}$ MPH'.

In the framework of the above-mentioned international study, 89/101 (88\%) patients with ADHD continued to receive open but controlled (visit every 2 nd month) treatment during a 12 month extension [21]. A total of 56 children $(63 \%)$ continued treatment until the end of the extension period. Compliance with treatment was assessed using questionnaires for parents and investigators, but no IOWA Conners data are available. Tolerability of treatment was still good and parents $(\sim 50 \%)$ and investigators $(\sim 75 \%)$ gave positive feedback. Unfortunately, adherence decreased by about half during the year, indicating that drop-out rates for this MPH-MR preparation differed little compared with the usual drop-out rates for IR preparations [17, 33]. Hence, the predicted long-lasting improvement in adherence with MPH-MR preparations was not observed in this study. However, it is important to also take into account the other benefits of switching from MPH-IR to MPH-MR preparations; e.g. it has been suggested that MPH-MR may be less prone to misuse or abuse compared with MPH-IR [31].

In an observational study in Brazil, patients with ADHD were switched from clinically stable MPH-IR treatment to MPH-SODAS ${ }^{\circledR}$ [24]. With its 8-week duration, the study provided information about effectiveness and satisfaction 
with MPH-SODAS ${ }^{\circledR}$, but not about long-term adherence. As for the above-mentioned study with OROS $^{\circledR}$ MPH, no information was given about the reason for switching. It is probable that clinically stable patients were just asked if they would like to take part in the planned study, so that both of these observational trials were 'real life' but not fully 'naturalistic'. This is in contrast to the OBSEER (OBservation of Safety and Effectiveness of Equasym $\mathrm{XL}^{\circledR}$ in Routine care) study reported in this supplement [12], the ADORE study [29], and a study on the effects of atomoxetine on ADHD in clinical paediatric treatment settings [3], which can all be considered as naturalistic-i.e. it was up to the physician which patients with ADHD were included in the study. The MPH-SODAS ${ }^{\circledR}$ switch study included only a small sample of children $(n=31)$ and adults $(n=23)$, with a protocol adherence of $70-80 \%$ after 8 weeks [24]. There were no significant changes in behavioural parameters and side-effects on MPH-SODAS ${ }^{\circledR}$, but the majority of patients were reported to be satisfied with switching (74\%). The authors stated that the latter "may reflect the convenience of once-daily dosing of this MPHextended release, as speculated in previous studies" [24], referring to a study in Taiwan [18].

Further publications from this Taiwanese research group $[9,17]$ looked at children with ADHD who adhered poorly to MPH-IR treatment and who were offered the chance to switch to MPH-OROS ${ }^{\circledR}$. Of 607 children with ADHD aged 5-16 years, $240(40 \%)$ were poorly adherent to treatment. A final subgroup of 124 children (originally 137; 13 were lost to follow-up) switched to MPH-OROS ${ }^{\circledR}$ and showed superior adherence and improved efficacy over a period of 3 weeks in an intra-individual comparison of MPH-IR versus MPH-OROS ${ }^{\circledR}$ use. This shows in principle that such a switch appears to work, at least in the short-term (3 weeks); however, only about half of the poor adherents to medication seemed to accept the offer. Reasons for, and determinants of, poor adherence may partly explain this

Table 1 Reasons for, and determinants of, poor adherence to MPHIR treatment

\begin{tabular}{ll}
\hline $\begin{array}{l}\text { Reasons (patients/parents } \\
\text { report) }\end{array}$ & Determinants (univariate analysis) \\
\hline $\begin{array}{l}\text { Forgetting medication } \\
\text { Side effects/safety concerns }\end{array}$ & $\begin{array}{l}\text { Older age } \\
\text { Increased frequency of drug } \\
\text { administration } \\
\text { Older age at onset/diagnosis }\end{array}$ \\
$\begin{array}{l}\text { Lack of perceived effect } \\
\text { Privacy issues }\end{array}$ & $\begin{array}{l}\text { Family history of ADHD } \\
\text { Bitter taste }\end{array}$ \\
Teacher objection & Higher mean dose of MPH \\
\hline
\end{tabular}

Switch to MPH-OROS ${ }^{\circledR}$ was based mainly on the decision of the investigator after mutual discussion with patients and their parents (according to Gau et al. [17]) observation (Table 1). This underlines the idea that the switch of MPH preparations itself (from MPH-IR to MPH$\mathrm{MR}$ in this case) is not the only factor affecting treatment adherence. Furthermore, switching preparations is usually accompanied by dosage increases and closer monitoring.

A switch to Medikinet ${ }^{\circledR}$ retard/XL (long-acting MPH with $50 \%$ MPH-IR) was explored in an open-label study of 447 patients (aged 6-17 years) who were either untreated (but considered suitable for such treatment) or currently receiving maintenance treatment with an approved MPH dosage form (IR or MR) [13]. Primary outcome measures were ADHD severity and side effects, which were evaluated by physicians and parents at the time of the medication changeover and 4-6 weeks later. ADHD symptom severity declined significantly, and oppositional behaviour and side effects, as assessed by parents, were also reduced. As expected, the strongest effects were found in patients without prior pharmacotherapy, but significant improvements were also observed in patients with once-daily or more than once-daily MPH-IR as prior medication, as well as Concerta ${ }^{\circledR}$.

Similarly, a switch to Equasym $\mathrm{XL}^{\circledR}$ was analysed in another open-label study performed in children aged 6-17 years, either untreated or currently receiving maintenance treatment with a different MPH formulation [11]. The majority (65\%) of the 308 patients enrolled demonstrated a positive response, which was also observed within the group who were previously treated with MPH-IR (64\%) and those treated with a different MPH-MR formulation $(55 \%)$. Most patients $(87 \%)$ were very or moderately satisfied with treatment.

Further results supporting a switch to MPH-MR formulations were obtained in the German multicentre, prospective, observational, naturalistic OBSEER study on the safety and effectiveness of Equasym $\mathrm{XL}^{\circledR}$, and are reported in this supplement $[6,12,14,28]$. OBSEER, planned and reported in line with the STROBE criteria (Table 2), collected behavioural data over a period of about 12 weeks from 822 children aged 6-17 years with ADHD. A total of $574(70 \%)$ children had been treated previously with other MPH formulations such as MPH-IR or MPH-MR. The treating physician decided independently, on the basis of his clinical assessment and experience, if treatment with Equasym $\mathrm{XL}^{\circledR}$ should be started. Therefore, the children did not need to be clinically stable on MPH-IR, as in the other switching studies described above. A subgroup of children $(n=371,45 \%)$ was switched from MPH-IR (once-daily: $n=101,12 \%$; repeated [i.e. administered several times per day]: $n=270,33 \%$ ) to MPH-MR. These children showed an improvement in all parameters investigated, including symptom reduction, satisfaction with treatment and quality of life [14, 28]. The MPH-IR oncedaily prior treatment subgroup showed improvements in adherence rates during Equasym $\mathrm{XL}^{\circledR}$ treatment that were 
Table 2 STROBE criteria and confirmation of items included for the OBSEER cohort study

\begin{tabular}{|c|c|c|c|}
\hline & $\begin{array}{l}\text { Item } \\
\text { No }\end{array}$ & Recommendation & \\
\hline \multirow[t]{2}{*}{ Title and abstract } & 1 & (a) Indicate the study's design with a commonly used term in the title or the abstract & $\boldsymbol{V}$ \\
\hline & & (b) Provide in the abstract an informative and balanced summary of what was done and what was found & $\checkmark$ \\
\hline \multicolumn{4}{|l|}{ Introduction } \\
\hline $\begin{array}{l}\text { Background/ } \\
\text { rationale }\end{array}$ & 2 & Explain the scientific background and rationale for the investigation being reported & $\checkmark$ \\
\hline Objectives & 3 & State specific objectives, including any prespecified hypotheses & $\boldsymbol{V}$ \\
\hline \multicolumn{4}{|l|}{ Methods } \\
\hline Study design & 4 & Present key elements of study design early in the paper & $\boldsymbol{V}$ \\
\hline Setting & 5 & $\begin{array}{l}\text { Describe the setting, locations, and relevant dates, including periods of recruitment, exposure, follow-up, } \\
\text { and data collection }\end{array}$ & $\checkmark$ \\
\hline \multirow[t]{5}{*}{ Participants } & 6 & $\begin{array}{l}\text { (a) Cohort study-Give the eligibility criteria, and the sources and methods of selection of participants. } \\
\text { Describe methods of follow-up }\end{array}$ & $\checkmark$ \\
\hline & & $\begin{array}{l}\text { Case-control study-Give the eligibility criteria, and the sources and methods of case ascertainment and } \\
\text { control selection. Give the rationale for the choice of cases and controls }\end{array}$ & \\
\hline & & Cross-sectional study — Give the eligibility criteria, and the sources and methods of selection of participants & \\
\hline & & (b) Cohort study-For matched studies, give matching criteria and number of exposed and unexposed & \\
\hline & & Case-control study_For matched studies, give matching criteria and the number of controls per case & \\
\hline Variables & 7 & $\begin{array}{l}\text { Clearly define all outcomes, exposures, predictors, potential confounders, and effect modifiers. Give } \\
\text { diagnostic criteria, if applicable }\end{array}$ & $\checkmark$ \\
\hline $\begin{array}{l}\text { Data sources/ } \\
\text { measurement }\end{array}$ & $8^{\mathrm{a}}$ & $\begin{array}{l}\text { For each variable of interest, give sources of data and details of methods of assessment (measurement). } \\
\text { Describe comparability of assessment methods if there is more than one group }\end{array}$ & $\checkmark$ \\
\hline Bias & 9 & Describe any efforts to address potential sources of bias & $\checkmark$ \\
\hline Study size & 10 & Explain how the study size was arrived at & $\boldsymbol{V}$ \\
\hline $\begin{array}{l}\text { Quantitative } \\
\text { variables }\end{array}$ & 11 & $\begin{array}{l}\text { Explain how quantitative variables were handled in the analyses. If applicable, describe which groupings } \\
\text { were chosen and why }\end{array}$ & $\checkmark$ \\
\hline \multirow[t]{6}{*}{ Statistical methods } & 12 & (a) Describe all statistical methods, including those used to control for confounding & $\checkmark$ \\
\hline & & (b) Describe any methods used to examine subgroups and interactions & $\checkmark$ \\
\hline & & (c) Explain how missing data were addressed & $\checkmark$ \\
\hline & & (d) Cohort study_-If applicable, explain how loss to follow-up was addressed & NA \\
\hline & & Case-control study_-If applicable, explain how matching of cases and controls was addressed & \\
\hline & & $\begin{array}{l}\text { Cross-sectional study - If applicable, describe analytical methods taking account of sampling strategy } \\
\text { (e) Describe any sensitivity analyses }\end{array}$ & NA \\
\hline \multicolumn{4}{|l|}{ Results } \\
\hline \multirow[t]{3}{*}{ Participants } & $13^{\mathrm{a}}$ & $\begin{array}{l}\text { (a) Report numbers of individuals at each stage of study-e.g. numbers potentially eligible, examined for } \\
\text { eligibility, confirmed eligible, included in the study, completing follow-up, and analysed }\end{array}$ & $\checkmark$ \\
\hline & & (b) Give reasons for non-participation at each stage & $\checkmark$ \\
\hline & & (c) Consider use of a flow diagram & $\checkmark$ \\
\hline \multirow[t]{3}{*}{ Descriptive data } & $14^{\mathrm{a}}$ & $\begin{array}{l}\text { (a) Give characteristics of study participants (e.g. demographic, clinical, social) and information on } \\
\text { exposures and potential confounders }\end{array}$ & $\checkmark$ \\
\hline & & (b) Indicate number of participants with missing data for each variable of interest & $\checkmark$ \\
\hline & & (c) Cohort study-Summarise follow-up time (e.g. average and total amount) & $\checkmark$ \\
\hline \multirow[t]{3}{*}{ Outcome data } & $15^{\mathrm{a}}$ & Cohort study-Report numbers of outcome events or summary measures over time & $\checkmark$ \\
\hline & & Case-control study_-Report numbers in each exposure category, or summary measures of exposure & \\
\hline & & Cross-sectional study-Report numbers of outcome events or summary measures & \\
\hline \multirow[t]{3}{*}{ Main results } & 16 & $\begin{array}{l}\text { (a) Give unadjusted estimates and, if applicable, confounder-adjusted estimates and their precision (e.g. } \\
95 \% \text { confidence interval). Make clear which confounders were adjusted for and why they were included }\end{array}$ & $\checkmark$ \\
\hline & & (b) Report category boundaries when continuous variables were categorized & \\
\hline & & (c) If relevant, consider translating estimates of relative risk into absolute risk for a meaningful time period & \\
\hline Other analyses & 17 & Report other analyses done-e.g. analyses of subgroups and interactions, and sensitivity analyses & $\boldsymbol{\nu}$ \\
\hline
\end{tabular}


Table 2 continued

$$
\text { Item Recommendation }
$$

No

\begin{tabular}{|c|c|c|c|}
\hline \multicolumn{4}{|l|}{ Discussion } \\
\hline Key results & 18 & Summarise key results with reference to study objectives & $\boldsymbol{\sim}$ \\
\hline Limitations & 19 & $\begin{array}{l}\text { Discuss limitations of the study, taking into account sources of potential bias or imprecision. Discuss both } \\
\text { direction and magnitude of any potential bias }\end{array}$ & $\boldsymbol{\sim}$ \\
\hline Interpretation & 20 & $\begin{array}{l}\text { Give a cautious overall interpretation of results considering objectives, limitations, multiplicity of analyses, } \\
\text { results from similar studies, and other relevant evidence }\end{array}$ & $\boldsymbol{V}$ \\
\hline Generalisability & 21 & Discuss the generalisability (external validity) of the study results & $\boldsymbol{V}$ \\
\hline \multicolumn{4}{|l|}{ Other information } \\
\hline Funding & 22 & $\begin{array}{l}\text { Give the source of funding and the role of the funders for the present study and, if applicable, for the } \\
\text { original study on which the present article is based }\end{array}$ & v \\
\hline
\end{tabular}

STROBE Statement-checklist of items that should be included in reports of observational studies

An Explanation and Elaboration article discusses each checklist item and gives methodological background and published examples of transparent reporting. The STROBE checklist is best used in conjunction with this article (freely available on the Web sites of PLoS Medicine at http://www.plosmedicine.org/, Annals of Internal Medicine at http://www.annals.org/, and Epidemiology at http://www.epidem.com/). Information on the STROBE Initiative is available at www.strobe-statement.org

${ }^{a}$ Given information separately for cases and controls in case-control studies and, if applicable, for exposed and unexposed groups in cohort and cross-sectional studies

similar to the other subgroups (prior treatment with MPHMR or 'other/not specified'), and a particular advantage was noted for the MPH-IR repeated prior treatment subgroup [28]. The positive effects were reflected by information from parents, teachers, children and physicians, and results were stable all day long. As in the other MPH-IR to MR switch studies, the dosage of MPH increased slightly following the transition. Interestingly, improvements were also noted in the subgroup of patients who switched from a different MPH-MR formulation to Equasym XL ${ }^{\circledR}$, although these were less marked than for the MPH-IR subgroups, as might be expected [14, 28].

\section{Conclusions}

Data from observational studies indicate that switching from one MPH preparation to another, specifically from MPH-IR to MPH-MR, but even from one MPH-MR formulation to another, appears to be a valid clinical approach that may contribute to treatment success. The observed improvement in various treatment outcomes might be best explained by the following factors: first, by the increased (and thus optimised) dose of MPH; second, the shorter intervals between visits directly after switching, leading to more intense psycho education and guidance; third, a positive expectation of improvement by all participants; and fourth, there might be an improvement in adherence in the long-term (short-term improvements have been shown $[9,17])$ accompanied by better general success of treatment, but this requires clarification in controlled studies.
In summary, within the framework of successful drug management of children and adolescents with ADHD, observational studies are necessary to refine the results and recommendations derived from RCTs, and enable further progress towards individualised medication.

Acknowledgments The authors would like to thank Amina Elsner, MD (Shire AG), for constructive review. The authors take full responsibility for the content of the paper but thank Joanna Wright, DPhil (Caudex Medical, Oxford, UK, supported by Shire Development Inc.) for editorial assistance and collating the comments of authors and other named contributors.

Conflict of interest Aribert Rothenberger has acted as a consultant or on advisory boards and/or as a speaker for Lilly, Shire Pharmaceuticals Ltd., Medice, Novartis and UCB. He has received research support from Shire Pharmaceuticals Ltd, the German Research Society and Schwaabe, and travel and educational grants from Shire Pharmaceuticals Ltd. Manfred Döpfner has received research grants and/or acted as a consultant or on advisory boards for Lilly, Shire Pharmaceuticals Ltd, Medice and Vifor.

This article is part of a supplement sponsored by Shire Development Inc.

Open Access This article is distributed under the terms of the Creative Commons Attribution Noncommercial License which permits any noncommercial use, distribution, and reproduction in any medium, provided the original author(s) and source are credited.

\section{References}

1. Antes G, Elm E (2008) Wie berichtet man eine Beobachtungsstudie? Deutsches Ärzteblatt 105:B6

2. Atzori P, Usala T, Carucci S, Danjou F, Zuddas A (2009) Predictive factors for persistent use and compliance of 
immediate-release methylphenidate: a 36-month naturalistic study. J Child Adolesc Psychopharmacol 19:673-681

3. Bakken RJ, Paczkowski M, Kramer HP, Axelson AA, Williams DW, Malcolm SK, Sumner CR, Kelsey DK (2008) Effects of atomoxetine on attention-deficit/hyperactivity disorder in clinical pediatric treatment settings: a naturalistic study. Curr Med Res Opin 24:449-460

4. Banaschewski T, Coghill D, Santosh P, Zuddas A, Asherson P, Buitelaar J, Danckaerts M, Dopfner M, Faraone SV, Rothenberger A, Sergeant J, Steinhausen HC, Sonuga-Barke EJ, Taylor E (2006) Long-acting medications for the hyperkinetic disorders. A systematic review and European treatment guideline. Eur Child Adolesc Psychiatry 15:476-495

5. Banaschewski T, Rothenberger A (2010) Pharmakotherapie mit Stimulanzien bei Kindern und Jugendlichen. In: Steinhausen HC, Rothenberger A, Dopfner M (eds) Handbuch ADHS. Kohlhammer, Stuttgart, pp 289-307

6. Becker A, Roessner V, Breuer D, Döpfner M, Rothenberger A (2011) Relationship between quality of life and psychopathological profile: data from an observational study in children with ADHD. Eur Child Adolesc Psychiatry. doi:10.1007/s00787-0110204-2

7. Britton A, McKee M, Black N, McPherson K, Sanderson C, Bain C (1998) Choosing between randomised and non-randomised studies: a systematic review. Health Technol Assess 2:1-124

8. Chacko A, Newcorn JH, Feirsen N, Uderman JZ (2010) Improving medication adherence in chronic pediatric health conditions: a focus on ADHD in youth. Curr Pharm Des $16: 2416-2423$

9. Chou WJ, Chou MC, Tzang RF, Hsu YC, Gau SS, Chen SJ, Wu YY, Huang YF, Liang HY, Cheng H (2009) Better efficacy for the osmotic release oral system methylphenidate among poor adherents to immediate-release methylphenidate in the three ADHD subtypes. Psychiatry Clin Neurosci 63:167-175

10. Claudot F, Alla F, Fresson J, Calvez T, Coudane H, Bonaiti-Pellie C (2009) Ethics and observational studies in medical research: various rules in a common framework. Int $\mathrm{J}$ Epidemiol 38:1104-1108

11. Dirksen SJ, D'Imperio JM, Birdsall D, Hatch SJ (2002) A postmarketing clinical experience study of Metadate CD. Curr Med Res Opin 18:371-380

12. Döpfner M, Görtz-Dorten A, Breuer D, Rothenberger A (2011) An observational study of once-daily modified-release methylphenidate in ADHD: effectiveness on symptoms and impairment, and safety. Eur Child Adolesc Psychiatry. doi:10.1007/s00787011-0202-4

13. Döpfner M, Breuer D, Ose C, Fischer R (2011) Methylphenidat mit modifizierter Freisetzung in der Routineversorgung - Wirksamkeit und Verträglichkeit eines Methylphenidat-Retard Präparates im klinischen Urteil und im Elternurteil - eine offene multizentrische Studie an Kindern und Jugendlichen mit ADHS. Monatsschrift fur Kinderheilkunde. doi:10.1007/s00112-0112413-7

14. Döpfner M, Breuer D, Walter D, Rothenberger A (2011) An observational study of once-daily modified-release methylphenidate in ADHD: the effect of previous treatment on ADHD symptoms, other externalising symptoms and quality-of-life outcomes. Eur Child Adolesc Psychiatry. doi:10.1007/s00787011-0205-1

15. Döpfner M, Gerber WD, Banaschewski T, Breuer D, Freisleder FJ, Gerber-von MG, Gunter M, Hassler F, Ose C, Rothenberger A, Schmeck K, Sinzig J, Stadler C, Uebel H, Lehmkuhl G (2004) Comparative efficacy of once-a-day extended-release methylphenidate, two-times-daily immediate-release methylphenidate, and placebo in a laboratory school setting. Eur Child Adolesc Psychiatry 13(Suppl 1):93-101
16. Findling RL, Quinn D, Hatch SJ, Cameron SJ, DeCory HH, McDowell M (2006) Comparison of the clinical efficacy of twicedaily Ritalin and once-daily Equasym XL with placebo in children with Attention Deficit/Hyperactivity Disorder. Eur Child Adolesc Psychiatry 15:450-459

17. Gau SS, Chen SJ, Chou WJ, Cheng H, Tang CS, Chang HL, Tzang RF, Wu YY, Huang YF, Chou MC, Liang HY, Hsu YC, Lu HH, Huang YS (2008) National survey of adherence, efficacy, and side effects of methylphenidate in children with attentiondeficit/hyperactivity disorder in Taiwan. J Clin Psychiatry 69:131-140

18. Gau SS, Shen HY, Soong WT, Gau CS (2006) An open-label, randomized, active-controlled equivalent trial of osmotic release oral system methylphenidate in children with attention-deficit/ hyperactivity disorder in Taiwan. J Child Adolesc Psychopharmacol 16:441-455

19. Hammer GP, du Prel JB, Blettner M (2009) Vermeidung verzerrter Ergebnisse in Beobachtungsstudien. Deutsches Ärzteblatt 41:664-668

20. Heger S, Trott GE, Meusers M, Schulz E, Rothenberger A, Rettig K, Medori R, Schreiner A, Remschmidt H (2006) Switching from a short-acting to a long-acting methylphenidate preparation: a multicentre, open study in children with ADHD. Z Kinder Jugendpsychiatr Psychother 34:257-265

21. Hoare P, Remschmidt H, Medori R, Ettrich C, Rothenberger A, Santosh P, Schmit M, Spender Q, Tamhne R, Thompson M, Tinline C, Trott GE (2005) 12-month efficacy and safety of OROS MPH in children and adolescents with attention-deficit/ hyperactivity disorder switched from MPH. Eur Child Adolesc Psychiatry 14:305-309

22. Hoekstra PJ (2010) The need for a long-term perspective in child and adolescent psychiatry. Eur Child Adolesc Psychiatry 19:687-688

23. Hollingworth SA, Nissen LM, Stathis SS, Siskind DJ, Varghese JM, Scott JG (2011) Australian national trends in stimulant dispensing: 2002-2009. Aust N Z J Psychiatry 45:332-336

24. Maia CR, Matte BC, Ludwig HT, Rohde LA (2008) Switching from methylphenidate immediate release to MPH-SODAS in attention-deficit/hyperactivity disorder. Eur Child Adolesc Psychiatry $17: 133-142$

25. McKee M, Britton A, Black N, McPherson K, Sanderson C, Bain C (1999) Methods in health services research. Interpreting the evidence: choosing between randomised and non-randomised studies. BMJ 319:312-315

26. Rapoport JL (2009) Personal reflections on observational and experimental research approaches to childhood psychopathology. J Child Psychol Psychiatry 50:36-43

27. Remschmidt H, Hoare P, Ettrich C, Rothenberger A, Santosh P, Schmidt M, Spender Q, Tamhne R, Thompson M, Tinline C, Trott GE, Medori R (2005) Symptom control in children and adolescents with attention-deficit/hyperactivity disorder on switching from immediate-release MPH to OROS MPH Results of a 3-week open-label study. Eur Child Adolesc Psychiatry 14:297-304

28. Rothenberger A, Becker A, Breuer D, Döpfner M (2011) An observational study of once-daily modified-release methylphenidate in ADHD: quality of life, satisfaction with treatment and adherence. Eur Child Adolesc Psychiatry. doi:10.1007/s00787011-0203-3

29. Rothenberger A, Coghill D, Döpfner M, Falissard B, Steinhausen HC (2006) ADORE (Attention-Deficit/Hyperactivity Disorder Observational Research in Europe). Naturalistic-observational studies in the framework of ADHD health care. Eur Child Adolesc Psychiatry 15:1-3

30. Rothwell PM (2005) External validity of randomised controlled trials: "to whom do the results of this trial apply?". Lancet 365:82-93 
31. Spencer TJ, Biederman J, Ciccone PE, Madras BK, Dougherty DD, Bonab AA, Livni E, Parasrampuria DA, Fischman AJ (2006) PET study examining pharmacokinetics, detection and likeability, and dopamine transporter receptor occupancy of short- and longacting oral methylphenidate. Am J Psychiatry 163:387-395

32. von Elm E, Altman DG, Egger M, Pocock SJ, Gotzsche PC, Vandenbroucke JP (2007) The Strengthening the Reporting of Observational Studies in Epidemiology (STROBE) statement: guidelines for reporting observational studies. PLoS Med 4:e296
33. Winterstein AG, Gerhard T, Shuster J, Zito J, Johnson M, Liu H, Saidi A (2008) Utilization of pharmacologic treatment in youths with attention deficit/hyperactivity disorder in Medicaid database. Ann Pharmacother 42:24-31

34. Zoega H, Baldursson G, Halldorsson M (2007) Use of methylphenidate among children in Iceland 1989-2006. Laeknabladid 93:825-832 